\title{
Conservative management of biopsy confirmed high-grade squamous intraepithelial lesions
}

\author{
Hederlingova $\mathrm{J}^{1}$, Redman ChW' ${ }^{2}$, Zahumensky $\mathrm{J}^{1}$ \\ 2nd Department of Gynaecology and Obstetrics, University Hospital of Comenius University, \\ Bratislava, Slovakia. jozef.zahumensky@gmail.com
}

\begin{abstract}
OBJECTIVES: Follow-up of women with biopsy-confirmed CIN2+ who were either treated immediately with LLETZ or managed conservatively to determine the rates of patients back on routine screening programme after a median of three years in two groups.

METHODS: In this retrospective study, 310 patients were involved who had undergone biopsy with result of CIN2+ between January 2011 and December 2014. Depending on the management, i.e. based on whether cytology and colposcopy follow-up or immediate treatment were performed, they were divided in two groups. Then the number of patients back on routine screening up to 15/2/2016 as well as the results of last cytology were compared within both groups.

RESULTS: A total of 310 women at average age of 30 years met the inclusion criteria. Of them, $230(74 \%)$ had immediate treatment whereas 80 (26\%) were managed conservatively. There were no statistically significant demographic differences between the two groups. The mean time of follow up was 1.091 days (2.98 years). The patients managed conservatively required more follow-up visits at colposcopy clinic $(p<0.001)$. The last documented cytology in the immediate treatment group was negative in $93 \%$ and low-grade/borderline in $7 \%$ of patients, while in the conservative management group, it was negative in $84 \%$, low-grade/borderline in $15 \%$ and high-grade in $1 \%$ of patients $(p=0.015)$. Overall, the proportions of patients who are back on routine screening recall are $96 \%$ and $87.5 \%$ for the immediate treatment and conservatively managed groups, respectively $(p=0.022)$.

CONCLUSION: The conservative management of high-grade CIN with cytology and colposcopic follow up is an OPTION in selected group of patients, but it cannot be routinely recommended (Tab. 2, Ref. 20). Text in PDF www.elis.sk.

KEY WORDS: conservative management, high-grade cervical intraepithelial lesions, colposcopy.
\end{abstract}

\begin{abstract}
Abbreviations: CIN - cervical intraepithelial neoplasia, LLETZ - large loop excision of transformation zone, NHSCSP - National Hospital Services Cervical Screening Programme, BSCCP - British Society for Colposcopy and Cervical Pathology, HPV - human papillomavirus, HR-HPV - high-risk human papillomavirus
\end{abstract}

\section{Introduction}

There is a general consensus that women diagnosed with highgrade CIN (CIN2+) should be treated. Recently, the immediate treatment of high-grade lesions (especially of CIN 2) has been called into question among adolescents and young women (aged $<25$ years) pointing at high regression rate of CIN 2 (62-70 \%) $(2,3)$ and the rarity of invasive carcinoma in this group $(4,5)$. Accordingly, it has been proposed that conservative management

${ }^{1}$ 2nd Department of Gynaecology and Obstetrics, University Hospital of Comenius University, Bratislava, Slovakia, and ${ }^{2}$ Colposcopy Unit, University Hospitals of North Midlands, Stoke-on-Trent, United Kingdom,

Address for correspondence: J. Zahumensky, MD, PhD, 2nd Department of Gynaecology and Obstetrics, University Hospital of Comenius University, Bratislava, Ruzinovska 6, SK-826 01 Bratislava, Slovakia. Phone: +421.918900860 with cytology and colposcopy follow up can be an option in certain groups of patients with proven CIN 2 (3). Apart from allowing potential spontaneous regression of CIN 2, this approach also avoids possible overtreatment and consecutive obstetric complications (6-8) in young patients.

These studies were in adolescents and women in their early twenties but we wanted to evaluate the suitability of a conservative approach of CIN2+ in women older than 25 years, and wishing future pregnancies.

\section{Methods}

This was a retrospective study using data from the colposcopy database at University Hospital of North Midlands, Stokeon-Trent. Women who had a colposcopically guided biopsy performed during the period from January 2011 to December 2014 and contained CIN2+ were included in the study. Patients who had previous treatment and those who were lost to the follow up were excluded from the study group.

Colposcopic examination and biopsy were performed by BSC$\mathrm{CP}$ certified colposcopists or trainees under supervision. The database included a number of demographic variables (age, parity, 
smoking habits), referral information, previous history at colposcopy, histologic results, subsequent colposcopy or/and cytology follow up. If the data on subsequent cytology had been missing, they were searched in the Open Exeter cytology database. We collected the data from biopsies performed till 15/2/2016.

The patients were divided in two groups: patients requesting conservative management (group 1) and those requesting immediate treatment who had a loop excision of the cervical transformation zone (group 2). The decision for conservative management was taken after colposcopy and discussion with the patient.

Patients who received immediate treatment were managed according to NHSCSP guidelines, i.e. they received a cure cervical test (cytology and high-risk HPV test) at 6 months. Should it show to be negative, they underwent cytology at 3 years. Patients in the conservatively managed group had colposcopy and a cervical cytology at 6 months (HR-HPV testing was not routinely available). The follow-up was scheduled for every six months until the patient is treated, or cytology becomes negative on two consecutive occasions or cervical test becomes HPV negative.

We compared the characteristics of the two groups using chisquare test for categorical variables and Mann-Whitney U test for the continuous variables. The alpha level was set at 0.05 . The time of follow up was calculated from the date when biopsy was taken up to $15 / 2 / 2016$. For the outcome we compared the last available cytology result, number of colposcopy visits after the biopsy, number of patients back on normal screening programme and number of hysterectomies in the two groups.

\section{Results}

A total of 371 women who had been CIN2+ diagnosed by cervical biopsy in given period of time were identified from the database. Twenty-eight patients who had had previous treatment and thirty-one who had been lost to the follow up were excluded from the study group, thus leaving a cohort of 310 patients. The patient characteristics and referral cytology findings are summarized in Table 1.

Tab. 1. Patient characteristics and referral cytology findings.

\begin{tabular}{lccc}
\hline & $\begin{array}{c}\text { Immediate treatment } \\
(\mathrm{n}=230)\end{array}$ & $\begin{array}{c}\text { Conservative } \\
\text { management (n=80) }\end{array}$ & $\mathrm{p}$ \\
\hline Age, y & $28(23-63)$ & $26(24-50)$ & 0.09 \\
\hline Parity & & & 0.06 \\
$\quad$ Nuliparous & $177(77 \%)$ & $58(72 \%)$ & \\
$\quad$ Primiparous & $13(6 \%)$ & $11(14 \%)$ & \\
$\quad$ Multiparous & $40(17 \%)$ & $11(14 \%)$ & 0.36 \\
\hline Smoking & & & \\
$\quad$ No & $149(65 \%)$ & $57(71 \%)$ & \\
$\quad$ Yes & $81(35 \%)$ & $23(29 \%)$ & \\
\hline Referral cytology & & & \\
Negative & $4(2 \%)$ & $4(5 \%)$ & \\
L-Grade/Borderline & $138(60 \%)$ & $55(69 \%)$ & \\
H-Grade & $88(38 \%)$ & $21(26 \%)$ & \\
\hline Punch biopsy result & & & \\
CIN 2 & $136(59 \%)$ & $71(89 \%)$ & \\
CIN 3 & $94(41 \%)$ & $9(11 \%)$ & \\
\hline Data are n (\%). Age is shown as median (range) &
\end{tabular}

Women in conservatively managed group tended to be younger and either nulliparous or primiparous but there were no statistically significant differences in the demographics or smoking habits between two groups.

There was a higher proportion of initial high-grade cytology in the immediate treatment group but the referral cytology did not influence the management significantly. The patients with histological result of CIN2 rather than those with CIN3 on initial biopsy were more likely to be managed conservatively $(\mathrm{p}<0.001)$.

Two hundred and thirty (74\%) had immediate treatment whereas eighty (26\%) were managed conservatively. Of those undergoing immediate treatment, high-grade disease (CIN2+) was found in $67 \%(\mathrm{n}=155), 42$ patients had CIN1 on histology results, and 32 had negative histologic specimens or HPV changes only. One case of stage 1a1 cervical cancer was detected.

The majority (71 \%) of the conservatively managed group has avoided treatment whilst $29 \%$ required further treatment with LLETZ. Only $32 \%$ of conservatively managed cases were discussed at the cervical screening multi-disciplinary meeting.

The mean time of follow up was 1.091 days (2.98 years). The patients managed conservatively received more follow-up visits $(\mathrm{p}<0.001)$.

The last documented cytology in the immediate treatment group was negative in $93 \%$ and low-grade/borderline in $7 \%$ of patients, while in the conservative management group, it was negative in $84 \%$, low-grade/borderline in $15 \%$ and high-grade in $1 \%$ of patients $(\mathrm{p}=0.015)$.

There were four cases of hysterectomy in the followed period in immediate treatment group and none in the conservative management group ( $\mathrm{p}=0.54)$. Overall, the proportions of patients who are back on routine screening recall are $96 \%$ and $87.5 \%$ for the immediate treatment and conservatively managed groups, respectively $(p=0.02)$.

\section{Discussion}

CIN 1 is a histologic diagnosis associated with HPV viral replication and regresses spontaneously in most cases (9). Although known for its precancerous potential, high grade CIN has also a certain potential to regress. In general, the regression rates for CIN 2 are higher than those for CIN3, but lower than those for CIN1. Some authors suggest that CIN 2 includes a heterogeneous collection of lesions with a subset of CIN2 behaving as a low-grade lesion $(10,11)$, requiring specific management rather that routine immediate treatment like that required in CIN 3. Several recent studies focused on CIN 2 management in young women under 25 years show high regression rates in this group of patients, varying from $39 \%$ to $71 \%(2,3,12,13)$. Although the regression rates seem to be higher in adolescent population than in adult women, nearly half of CIN 2 will resolve if left untreated in adults (14). Discacciati studied a cohort of women with the diagnosis of CIN2 aged 19-43 and found no significant association with their age at diagnosis with progression or regression of CIN2 at the end of the observed 12-month period (15). 
Tab. 2. Follow-up of the patients.

\begin{tabular}{lccc}
\hline & $\begin{array}{c}\text { Immediate } \\
\text { treatment } \\
(\mathrm{n}=230)\end{array}$ & $\begin{array}{c}\text { Conservative } \\
\text { management } \\
(\mathrm{n}=80)\end{array}$ & $\mathrm{p}$ \\
\hline $\mathrm{N}^{\circ}$ visits at colposcopy & $0(0-9)$ & $1(0-7)$ & $<0.001$ \\
\hline Last Cytology & $215(93 \%)$ & $67(84 \%)$ & 0.015 \\
$\quad$ Negative & $15(7 \%)$ & $12(15 \%)$ & \\
L-Grade/Borderline & 0 & $1(1.25 \%)$ & \\
H-Grade & $10(4 \%)$ & $10(12.5 \%)$ & 0.022 \\
\hline Back on routine screening & $220(96 \%)$ & $70(87.5 \%)$ & \\
$\quad$ No & & & 0.54 \\
Yes & $226(98 \%)$ & $80(100 \%)$ & \\
\hline Hysterectomy & $4(2 \%)$ & 0 & \\
No & & & \\
Yes & & & \\
\hline Data are n (\%). Number of visits at colposcopy is shown as median (range)
\end{tabular}

In our study, we followed women at average age of 30 years who have not had CIN2+ (including CIN2 and CIN3) treated immediately after histological diagnosis. About a third of these women required further treatment and none underwent hysterectomy. The last cytology result in the follow-up period in this group was negative in $84 \%$ and low-grade/borderline in $15 \%$, while there was only one case of high-grade cytology found. These numbers support the evidence of regression potential of high-grade CIN: the fact that $86 \%$ of patients who avoided treatment were able to display normal screening results suggests that conservative management can be a reasonable option.

This study did not specifically document why and on what parameters the conservative management had been chosen. It is reported that the regression rates for CIN2 seem to be higher when the referral cytology is low-grade/ASCUS rather than high-grade (15). When CIN2 diagnosis on biopsy is made after a high-grade smear, the patients are more apt to have underlying CIN3 (11). In our study, there was no significant association with the index cytology. The specificity of colposcopy examination is not very high, especially for low-grade lesions (17). The colposcopic appearance of lesions would have been a factor in deciding the management. It has been noted that normal and low-grade colposcopic impression with CIN2 on biopsy is strongly associated with minor cone histology (18). In other study, the regression rates of CIN2 were higher in women whose lesions were restricted to one quadrant when compared to those with lesion extending to one or more quadrants (15).

Some other predictive factors may help decide whether conservative management is a safe option. Persistent HPV infection, especially HPV 16/18 is associated with the risk of progression to higher CIN $(2,11,16)$. In our study, the data on HR-HPV testing were unavailable in half of the cases and therefore not included in the analysis. HPV genotyping and some other biomarkers like P16 protein expression might be useful when deciding possible management options $(19,20)$.

There is a need for cautious approach to conservative management of high-grade lesions. In terms of cervical cancer prevention, the safest management obviously lies in immediate treatment after the diagnosis of CIN2+. In our immediate treatment cohort, $96 \%$ of patients are back on routine screening recall and in $93 \%$, their last cytology was negative. Nevertheless, some cases may call for a different approach, like those of young nulliparous patients with CIN 2 on biopsy and normal colposcopic findings. Best practice would be to discuss every such patient on multidisciplinary meetings where cytology and histology results are reviewed, HPV genotyping considered and future management of the patient discussed. Every patient should be informed about the possible management options, and their benefits and risks. If opting for conservative management, good compliance is absolutely necessary for the sake of careful cytology and colposcopy follow-up (Tab. 2).

These considerations underline the need for further prospective studies with specific inclusion criteria to identify the group of patients that is most suitable for conservative management as well as to define the protocols of follow-up to lower the risk of potential progression to higher grade CIN.

\section{References}

1. Massad LS, Einstein MH, Huh WK et al. 2012 updated consensus guidelines for the management of abnormal cervical cancer screening tests and cancer precursors. Obstet Gynecol 2013; 121: 829-846.

2. Moscicki AB, Ma Y, Wibbelsman C, et al. Rate of and risks for regression of CIN 2 in adolescents and young women. Obstet Gynecol 2010; 116: $1373-1380$.

3. McAllum BE, Sykes PH, Sadler L, Macnab H, Simcock BJ, Mekhail AK. Is the management of CIN 2 always necessary in women under 25 years old? Am J Obstet Gynecol 2011; 205: 478.e17.

4. Popadiuk C, Stankiewicz A, Dickinson J, Pogany L, Miller AB, Onysko J. Invasive Cervical Cancer Incidence and Mortality Among Canadian Women Aged 15 to 29 and the Impact of Screening. J Obstet Gyneacol Can 2012; 34 (12): 1167-1176.

5. Castanon A, Leung VM, Landy R, Lim AW, Sasieni P. Characteristics and screening history of women diagnosed with cervical cancer aged 20-29 years. Br J Cancer 2013; 109 (1): 35-41.

6. Heinonen A, Gissler M, Riska A, Paavonene J, Tapper AM, Jakobsson M. Loop Electrosurgical Excision Procedure and the Risk for Preterm Delivery. Obstet Gynecol 2013; 121: 1063-1068.

7. Kyrgiou M, Koliopoulous G, Martin-Hirsch P, Arbyn M, Prendiville W, Paraskevaidis E. Obstetric outcomes after conservative treatment for intraepithelial or early invasive cervical lesions: systematic review and meta-analysis. Lancet 2006, 367 (9509): 489-498.

8. Miller ES, Grobman WA. The association between cervical excisional procedures, midtrimester cervical length, and preterm birth. Am J Obstet Gynecol 2014; 211: 242.e1-244.

9. Hordning U, Junge J, Rygaard C, Lundvall F. Management of lowgrade CIN: Follow-up or treatment? Eur J Obstet Gynecol Reprod Biol 1995; 62: 49-52.

10. Wilkinson TM, Sykes PHH, Simcock B et al. Recurrence of highgrade cervical abnormalities following conservative management of cervical intraepithelial neoplasia grade 2. Am J Obstet Gynecol 2015; 212: 769.e1-7.

11. Castle PE, Schiffman M, Wheeler CM, Solomon D. Evidence for frequent regression of cervical intraepithelial neoplasia-grade 2. Obstet Gynecol 2009; 113: 18-25. 
12. Fuchs K, Weitzen S, Wu L, Phipps MG, Boardman LA. Management of cervical intraepithelial neoplasia 2 in adolescent and young women. J Pediatric Adolescent Gynecol 2007; 20 (5): 269-274.

13. Monteiro DL, Trajano AJ, Russomano FB, Silva KS. Prognosis of intraepithelial cervical lesion during adolescence in up to two years of follow-up. J Pediatr Adolesc Gynecol 2010; 23 (4): 230-236.

14. Syrjanen K, Kataja V, Yliskoski M, Chang F, Syrjanen S, Saarikoski S. Natural history of cervical human papillomavirus lesions does not substantiate the biologic relevance of the Bethesda system. Obstet Gynecol 1992; 79 (5 Pt 1): 675-682.

15. Discacciati MG, de Souza CAS, d'Otavianno MG, et al. Outcome of expectant management of cervical intraepithelial neoplasia grade 2 in women followed for 12 months. Eur J Obstet Gynecol Reprod Biol 2011; 155: 204-208.

16. Castle PE, Stoler MH, Solomon D, Schiffman M. The relationship of community biopsy-diagnosed cervical intraepithelial neoplasia grade 2 to the quality control pathology-reviewed diagnoses: An alts report. Am J Clin Pathol 2007; 127 (5): 805-815.
17. Cantor SB, Cárdenas-Turanzas M, Cox DD et al. Accuracy of colposcopy in the diagnostic setting compared with the screening setting. Obstet Gynecol 2008; 111 (1): 7-14.

18. Giannella L, Mfuta K, Gardini G, Rubino T, Fodero C, Prandi S. High-grade CIN on cervical biopsy and predictors of the subsequent cone histology results in women undergoing immediate conization. Eur J Obstet Gynecol Reprod Biol 2015; 186: 68-74.

19. Klaes R, Benner A, Friedrich T et al. p16INK4a immunohistochemistry improves interobserver agreement in the diagnosis of cervical intraepithelial neoplasia. Am J Surg Pathol 2002; 26: 1389-1399.

20. Spiryda LB, Whitaker KM, Messersmith A, Banister CE, Creek KE, Pirisi-Creek LA. Clinical Utility of Molecular Biomarkers in Cervical Squamous Intraepithelial Lesions in a Young Adult Population. J Low Genit Tract Dis 2016; 20 (1): 26-30.

Received June 16, 2017. Accepted July 13, 2017. 